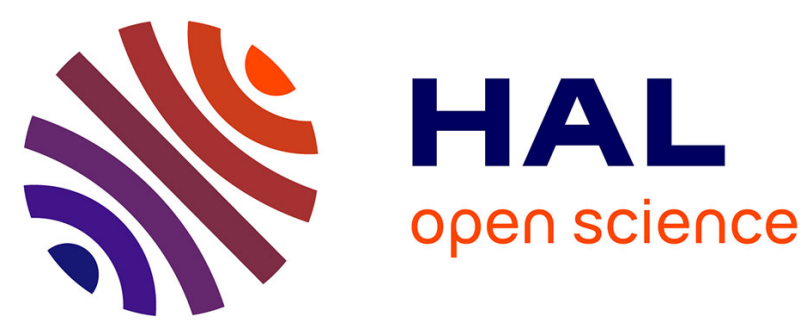

\title{
Towards an Approach to Link Knowledge and Prediction in Product Design
}

Bertrand Marconnet, Frédéric Demoly, Davy Monticolo, Samuel Gomes

\section{To cite this version:}

Bertrand Marconnet, Frédéric Demoly, Davy Monticolo, Samuel Gomes. Towards an Approach to Link Knowledge and Prediction in Product Design. 12th IFIP International Conference on Product Lifecycle Management (PLM), Oct 2015, Doha, Qatar. pp.248-258, 10.1007/978-3-319-33111-9_23 . hal-01377448

\section{HAL Id: hal-01377448 \\ https://inria.hal.science/hal-01377448}

Submitted on 7 Oct 2016

HAL is a multi-disciplinary open access archive for the deposit and dissemination of scientific research documents, whether they are published or not. The documents may come from teaching and research institutions in France or abroad, or from public or private research centers.
L'archive ouverte pluridisciplinaire HAL, est destinée au dépôt et à la diffusion de documents scientifiques de niveau recherche, publiés ou non, émanant des établissements d'enseignement et de recherche français ou étrangers, des laboratoires publics ou privés. 


\title{
Towards an approach to link knowledge and prediction in product design
}

\author{
Bertrand Marconnet $^{1}$, Frédéric Demoly ${ }^{1}$, Davy Monticolo ${ }^{2}$, Samuel Gomes ${ }^{1}$ \\ ${ }^{1}$ IRTES-M3M, UTBM, Université Bourgogne Franche-Comté, France \\ ${ }^{2}$ Institut National Polytechnique de Lorraine (Lorraine INP), France \\ ${ }^{1}\{$ bertrand.marconnet, frederic.demoly, samuel.gomes $\} @$ utbm.fr \\ 2 davy.monticolo@univ-lorraine.fr
}

\begin{abstract}
Nowadays the knowledge reuse in product design is part of the main challenging issues in product lifecycle management, especially in the earlier stages. Indeed, over the last decade concurrent engineering principles have introduced numerous constraints to be well balanced and considered in product design regarding the whole product lifecycle. Designers need to be aware of their decisions and require assistance in their routine activities. As such, the authors propose to tackle this issue by introducing the concept of generating predictions (future) so as to activate knowledge (past) in the design process (present). Thus the fact of associating knowledge and prediction to ensure the appropriate knowledge reuse in product design by designers will require the capture of specific design context. A mechanical assembly as a case study is presented to illustrate the approach.
\end{abstract}

Keywords: Knowledge reuse, Prediction, Product design, PLM.

\section{Introduction}

Nowadays, knowledge reuse is part of the major stakes in product lifecycle management (PLM), especially in the early design phases. Indeed, such issue requires an appropriate process to ensure a full understanding of designer and an assistance in product design. An interesting way to tackle this research issue consists in capturing the past (knowledge) and generating future actions (predictions) so as to ensure awaress in the present with an appropriate knowledge activation. The management of knowledge, information and prediction can be seen as strategic in indutry. Currently, knowledge reuse leads to difficulties due to the complexity of the evolution of business rules in the PLM. The cost of interoperability barrier between engineering and manufacturing departments since several years is estimated to one billion/year in the US automotive industry [1]. Moreover, the decision-making process in product design requires the collection of constraints and knowledge in the appropriate context. As such, designers are aided in their design activities with the support of models, methods and tools covering the product lifecycle. Here knowledge management assists users in decision-making and data structuring, however right decisions need to 
be associated to suitable business context [3]. A full understanding of the design context and intents is needed to make a decision, as well as its impacts in the product lifecycle. At this stage, an innovative investigation consists in generating the future in design, so as to define a future-oriented design context and then improve knowledge reuse.

In this paper, a state of the art in the fields of knowledge reuse in PLM, concurrent and proactive engineering and prediction generation is proposed. Built on this, the authors introduces their efforts related towards a novel approach to like predictions with knowledge in product design.

\section{State of the art}

\subsection{Knowledge reuse in PLM}

Knowledge can be described as tacit and explicit notions. Two concepts composed knowledge (K), i.e. data (D) and information (I). Actually data, information and knowledge are quite related, since "data is the raw material of information, and information is the raw material of knowledge". Data is a real and verifiable object, and is considered as a quantitative and objective fact [4]. Song et al. described knowledge in PLM as $\mathrm{K}=$ I.E.S.A or $\mathrm{K}$ represents Knowledge, I for Information, $\mathrm{S}$ for Skills, E for Experience and A for Attitude. PLM systems is often associated to many applications (e.g. Computer-Aided Design - CAD, Computer Aided Manufacturing - CAM, etc.) at different phases of the product lifecycle integrated with information systems (i.e. Product Data Management - PDM, Manufacturing Process Management - MPM, etc.) by using knowledge bases. This is actually done with the support of interesting approaches in the fields of Design for X and Design to $\mathrm{X}$ to name a few [5]. However deficiencies have been identified with PDM procedures, particularly with the knowledge reuse process [6], since engineers spend $60 \%$ of their time to search the right information [7]. Indeed, $75 \%$ in the design activities, includes the reuse of existing knowledge and this explains why $30 \%$ of designers spend of their working time in knowledge acquisition and dissemination in the product development process [8]. This fact is the result of the partial dissemination of appropriate knowledge representation into the earlier phases of collaborative design [9]. To tackle this issue, it is important to improve knowledge reuse by proposing a suitable set of knowledge consistent with design intents and design context [10]. Knowledge reuse is therefore a challenging issue so as to ensure designers' awareness in their activities.

\subsection{Concurrent and proactive engineering}

Concurrent engineering is considered as commonly used in industry, in order to integrate knowledge and constraints from product lifecycle in product design. But 
qualitative information and knowledge are not yet well exploited due to their relationships complexity. A novel philosophy, also called Proactive engineering, enables the integration of downstream processes in the early design stages before product geometry is defined [11]. Intent can be described as a plan action based on two mechanisms, causality and intentionality [12]. In product design, intent is often considered as a capture of a goal intention [13], which is incorporated in CAD systems through geometric specifications based on functionalities of the product [14]. In addition, design intent need to be well interpreted in PLM to ensure awareness of their decisions as early as possible via contextualized design knowledge [10]. As a consequence, collecting input and output data in CAD systems (i.e. parameters, behavior, relationships, etc.) is based on the constraints network and the deduction of logic. In general, the representation of parametric models is based on either disordered or ordered collection of constraints in product design, and has a role to play in the description of design intents. Besides, the definition of specific context in engineering design, is considered as sets of constraints in order to influence the behavior of a system embedded in a given task [15]. With the expression of explicit and formal representation of the design concept and its terminology through knowledge, the design plan includes two aspects. One relates to the need, objectives and constraints in product design (i.e. product relationships). By understanding the current design context, the interpretation and representation of design intent in a formal manner can be done via ontology models. A this stage, a context-awareness is got in a context situation so as to reuse the right knowledge at the right time [16]. Here, context-awareness is a term which provides relevant information and/or services to the user, and has the ability to describe sense and act upon information in computer, about its environment such as location, time, and temperature or user identity [17]. The fact of interpreting the context and the intent, enable the generation of predictions in the early design stages in order to activate knowledge and make awareness designers.

\subsection{Prediction generation}

The fact of being aware of the future state in a given situation is defined as the ability to act on the preparation of some effects or future states in the environment. The concept of prediction can be referred with others such as anticipation, forecast, augury, prognosis, etc. Prediction can be defined as "a representation of a particular future event" [18]. The ambiguity of the anticipation word is described as a represented action in order to project in the future the expected results through a cognitive action and/or strategic representation of an implementation. Concept of prediction is considered as a view from experiments on machine learning, especially in the field of the artificial intelligence. For example, estimated by a probabilistic methods, events that may occur in a given state are used to generate events, such as genetic algorithms, fuzzy logic, neural networks, constraint satisfaction problems and Bayesian networks to name a few. All these methods are quite different from a reasoning point of view, especially the resolution and ability to incorporate uncertainties. In engineering, two kinds of prediction can be identified, the behavioral prediction process and the action prediction process [19]. The first one relates the 
prediction of the product behavior (e.g. Finite Element Analysis), using simulation tools like CAE (Computer Aided Engineering) in order to exploit and interpret design data. Predictive engineering allows adjusting some parameters and characteristics of a product by considering as a beneficial influence of anticipation. The capability to generate a partial future is considered as a strong benefit to select the prediction before acting [20]. Programmed obsolescence is the best example, which is able to predict in advance the reliability of usury product. The second kind of prediction is the anticipation of design activities to highlight the evolution or the robustness of product assembly [21]. For example in a mechanical engineering, academic works evaluate the reasonableness of tolerance allocation, with a method to manage extracted information of a CAD assembly model, by generating automatically a 3D assembly dimensions chains with an ant colony algorithm in a Geometric Dimensioning and Tolerancing (GD\&T) systems [22]. The evaluation of the allocation of tolerance is the next step to recognise "the acceptance of a production percentage" [23], and evaluate the robustness of a design solution space, tolerancing and the feasible geometry. In the field of maintenance, prediction is also used to know the moment to change a physical part in order to anticipate and avoid potential failure of product or machine. Thus prediction could be defined by the notion of alternative based on contextual information.

\section{Clarification of terms around knowledge and prediction}

The research objective aims at generating prediction from a specific design context so as to activate and reuse knowledge in product design. [24]. This section therefore clarify terms around knowledge and prediction In literature, different kinds of knowledge are described, such as declarative, temporal, procedural, and causal [4] [25].

The Figure 1 illustrates the representation such kinds of knowledge between the past, present, and future timeline.

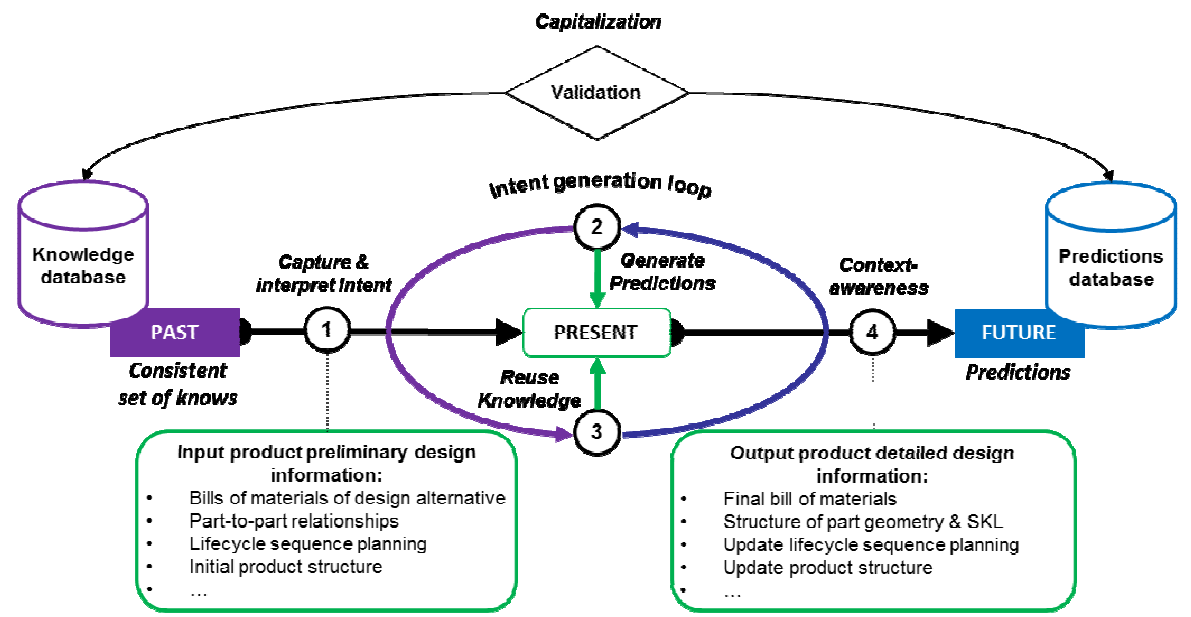

Fig. 1. General view of knowledge and prediction in a timeline 
Designers need to have appropriate knowledge during the product design process. This firstly requires the capture and interpretation of designers' intents from the early design stages (Step $\square$ ) so as to generate predictions. Design intents are built upon previous defined information (i.e. bill of materials, part-to-part relationships, etc.), to evaluate admissible solutions (i.e. lifecycle planning) in order to propose a product structure related to the design context (Step $\square$ ). Different kinds of knowledge are checked (Step $\square$ ) and activated in order to ensure the reused of the right knowledge in the right design context (Step $\square$ ).

To illustrate our research vision, different definitions of terms have to be introduced. As such, Table 1 presents for each term a definition and related componants.

Table 1. Definitions.

Term Qualitative \& formal description Componant

\begin{tabular}{|c|c|c|}
\hline Information & $\begin{array}{l}\text { Based on data that is often considered as a quantitative } \\
\text { and objective facts. Information represents the data context } \\
\text { and which is considered as a the structure of relationships } \\
\text { (requirements, objectives and constraints) }\end{array}$ & $\begin{array}{ll}\text { - } & \text { Context } \\
\text { - } & \text { Relationships }\end{array}$ \\
\hline Context & $\begin{array}{l}\text { Needs, objectives or constraints interpreted for product } \\
\text { design. "The context is any information that can be used to } \\
\text { characterise the situation of an entity. An entity is a person, } \\
\text { place, or object that is considered relevant to the } \\
\text { interaction between the user and the application } \\
\text { including the user and the application themselves" } \\
{[26]}\end{array}$ & $\begin{array}{ll}\text { - } & \text { Environment } \\
\text { - } & \text { Task } \\
\text { - } & \text { Activity } \\
\text { - } & \text { Process } \\
\text { - } & \text { Role } \\
\text { - } & \text { Ressource } \\
\text { - } & \text { Expertise }\end{array}$ \\
\hline Intent & $\begin{array}{l}\text { Design rationale by capturing and interpreting the context } \\
\text { in spreading input/output data of design feature like } \\
\text { parameter, behavior, or relationship }\end{array}$ & $\begin{array}{l}\text { - } \quad \text { Geometric constraint, } \\
\text { Part-to-part } \\
\text { relationship } \\
\text { constraint }\end{array}$ \\
\hline Knowledge & $\begin{array}{l}\text { Contextualised information which is deduced and } \\
\text { integrated, based on a set of a knowledge: Declarative } \\
\text { (Know-WHAT of designer's intent), Temporal (Know- } \\
\text { WHEN and Know-WHERE of temporal event), Procedural } \\
\text { (Know-HOW of planner intent), and Causal knowledge } \\
\text { (Know-WHY of the rationale) }\end{array}$ & $\begin{array}{ll}\text { - } & \text { Information } \\
\text { - } & \text { Context } \\
\text { - } & \text { Set of knowledge: } \\
\text { Declarative, } \\
\text { Temporal, } \\
\text { Procedural, and } \\
\text { Causal } \\
\text { knowledge }\end{array}$ \\
\hline
\end{tabular}


Situated at the same cognitive level than knowledge, the difference is the generation of alternative solutions (e.g. lifecycle planning). The fundamental principle of prediction is the determinist (dependent on an initial condition to an instant $t$ ) describes by the principle of causality (evolving in a dependent state of his past or his present condition). Generate predictions is based on contextual information, by proposing alternatives, where knowledge can check and activate temporal knowledge

Recognised as a knowledge item that describes rules and facts, laws. Such knowledge requires an action and is activated by procedural and temporal knowledge
- Information

- Context

- Alternative

(e.g. Assembly sequence, Assembly operation,

Manufacturing

operation, etc.)

- Design rules

- Parameters

- Definition of geometry entity

- Material details

- Business term

Describes the context from a temporal and location point of view. Without such knowledge, declarative knowledge are considered as inactive and procedural knowledge can be activated by representing and understanding the evolution of a temporal information based on constraints

Temporal Knowledge

Procedural

Description of a step for action. Interpreted as a dynamic/action knowledge following sequence in a contextual situation
Time of assembly sequence, assembly operation,

manufacturing operation, etc.
- $\quad$ Business process

- Design method

\& technics

- Mathematical

Calculation

- Business experience

- Use case

- New design rules

- Functional requirement

We propose to apply these terms into a framework which links predictions and knowledge in product design hereafter.

\section{Approach to link knowledge and prediction}

The Figure 2 introduces a proactive design framework based on causal design [25] [11]. This means that this framework aims at generating predictions of the future so as to activate and reuse the appropriate knowledge of the past into product design stages (present). This framework therefore allows understanding how designer lead its activities by interpreting its intents, and ensure the knowledge reuse at the right time. 


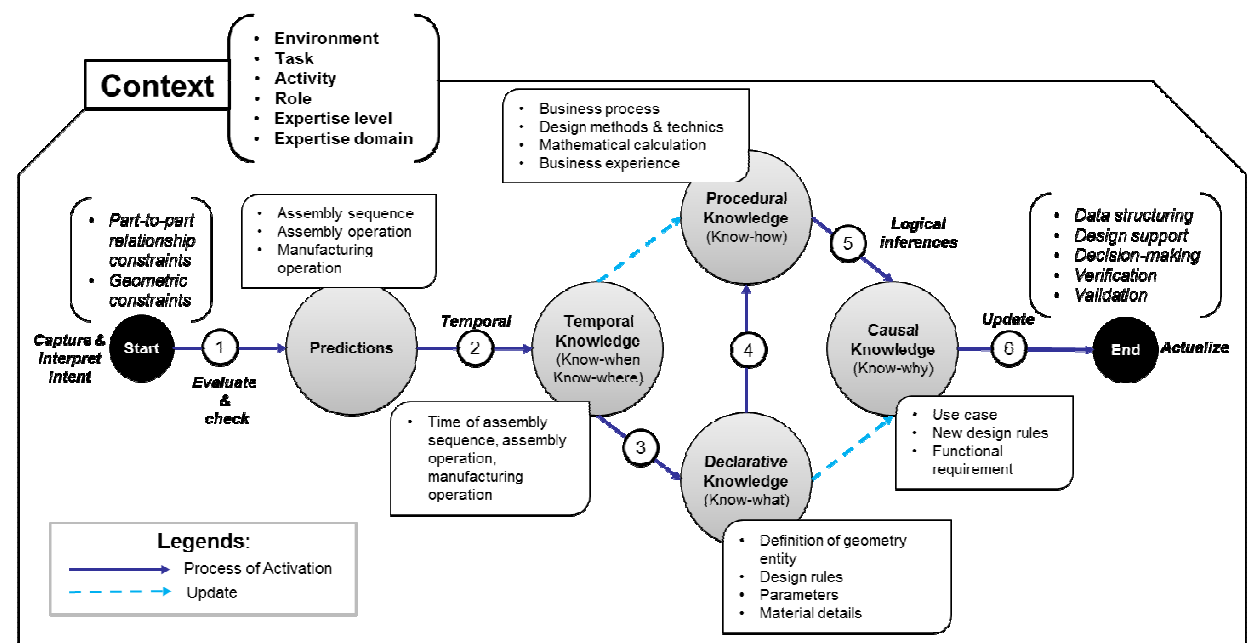

Fig. 2. Framework of Prediction-Knowledge-Context association [11] [25]

Step 1: Once the context (environment, task, activity, etc.) has been captured, design intent (i.e. geometric constraints, part-to-part relationships) is interpreted in order to generate prediction.

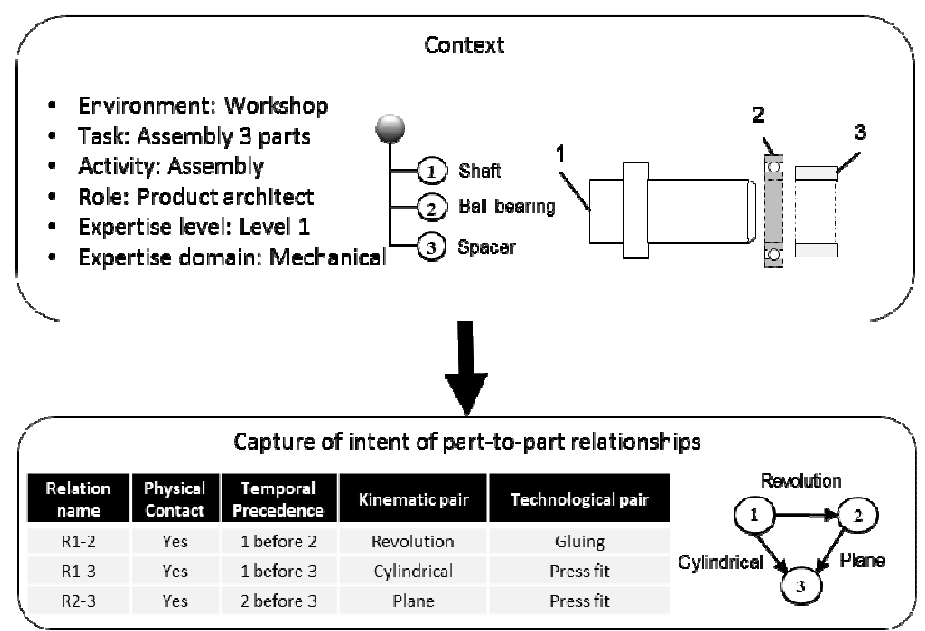

Fig. 3. Capture of design intent through part-to-part relationships

Step 2: Design intents are interpreted to assess alternative solutions (Step $\square$ of Fig. 2). Built on this, admissible lifecycle planning (i.e. assembly and manufacturing sequence planning, etc.) are generated and evaluated as predictions from a design phase point of view. 


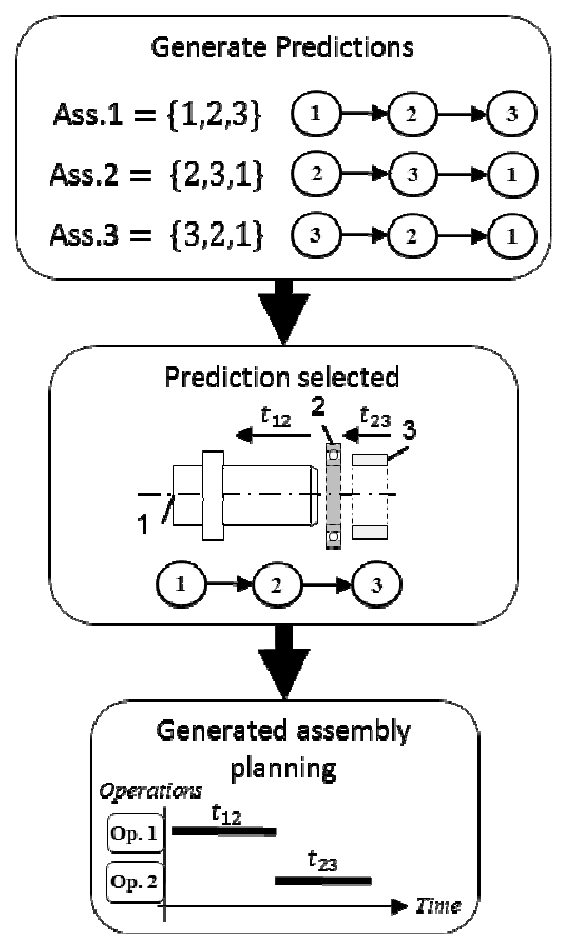

Fig. 4. Generation of predictions related to assembly planning phase

Step 3: Selected predictions are transformed into temporal rules (Step $\square$ of Fig. 2) and temporal knowledge by checking design intents and therefore lead to the activation of declarative knowledge (Step $\square$ of Fig. 2), with the appropriate knowledge (i.e. design rules, parameters, etc.). Procedural knowledge (i.e. business process model, design methods and technics, mathematical calculation, etc.) is then activated (Step $\square$ of Fig. 2) with the temporal and declarative knowledge, into a step/sequence of actions. Logical inferences are based on procedural knowledge with the aid of ontology model, in order to generate causal knowledge (Step $\square$ of Fig. 2). In the causal network, effect/impact on other knowledge relationships, are activated in order to find alternative knowledge, new knowledge or hidden knowledge useful for the designer (i.e. use case, etc.). 


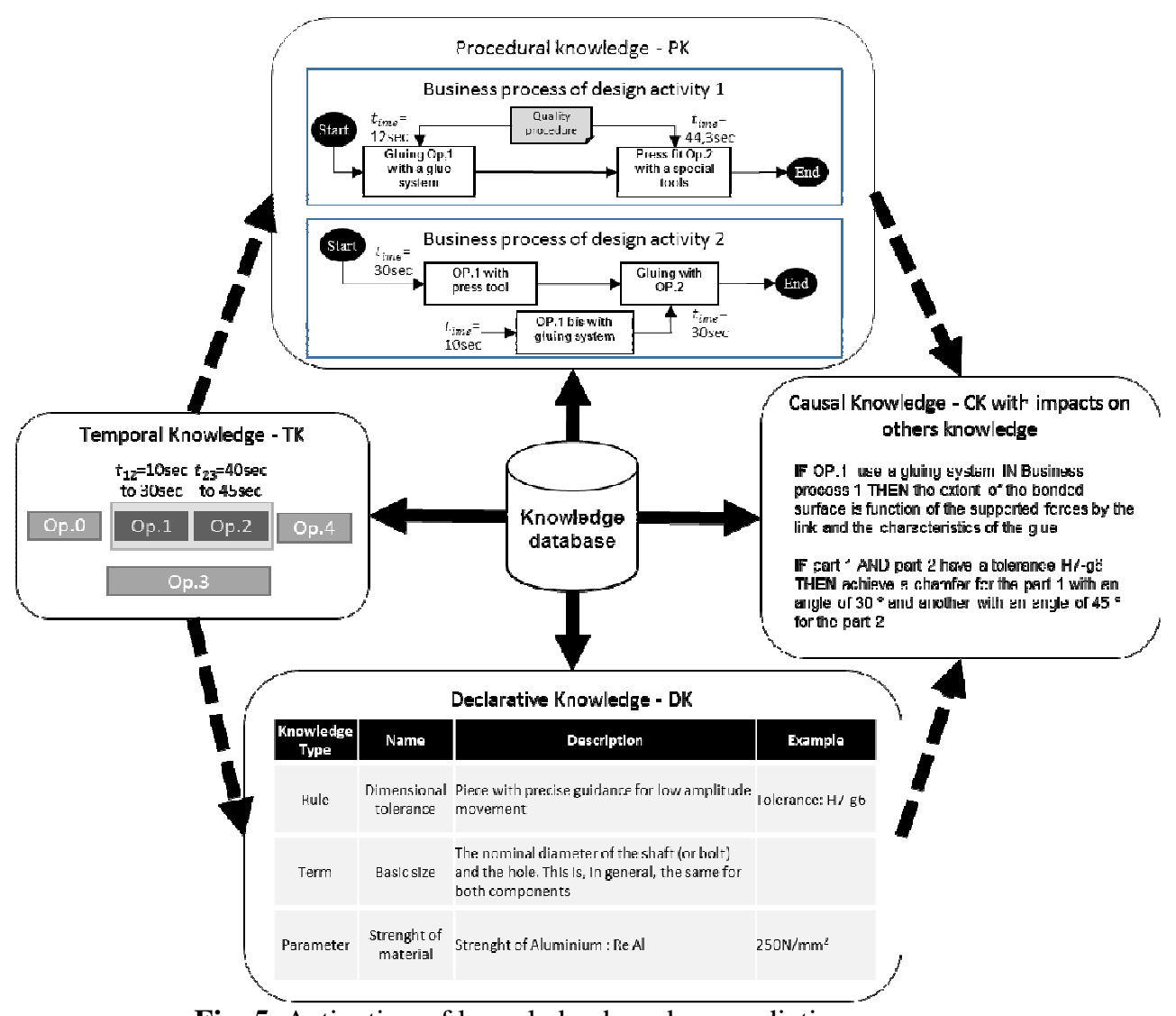

Fig. 5. Activation of knowledge based on prediction

Step 5: Designer interprets this set of knowledge (Step $\square$ of Fig. 2) (i.e. data structuring, design support, verification and validation) by injecting in the appropriate format (i.e. update sequence planning, structure of assembly operation, product structure, etc.) a qualitative description to the right person at the right place.

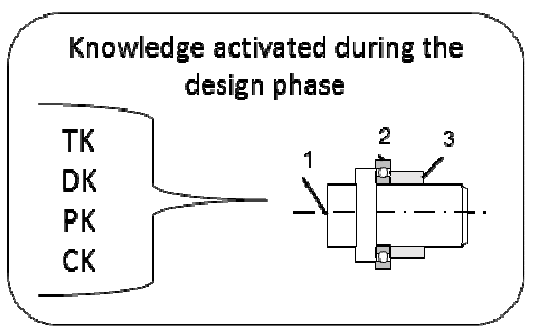

Fig. 6. Proposition of appropriate knowledge reuse in product design 


\section{Conclusions and future work}

This paper has presented an overview of the current researches and challenges in prediction generation and knowledge reuse approaches. This has highlighted a research initiative towards the description of prediction-knowledge associations so as to improve current knowledge reuse process in product design. A typology of knowledge has been defined as well as their interrelationships and their links with designer's context and predictions. Future work will address the development of reasoning procedures in order to automatically capture design context and intents, and later the knowledge activation and reuse from a knowledge base in CAD systems. Moreover, semantic technology will be studied as a solution for such effort, especially for the description of prediction-knowledge relationships. As such, a multi-agents system would be a suitable system to support knowledge activation and reuse from an autonomous manner.

Acknowledgments. The author would like to thank ACCELINN company for this collaboration and all financial supports of this research and technology program. This research work is made in collaboration with IRTES-M3M lab, as part of a CIFRE contract (Industrial Standards of Research Training) by the French National Agency for Research and Technology (ANRT).

\section{References}

[1] T. Gregory, "Interoperability Cost Analysis of the U.S. Automotive Supply Chain," National Institute of Standards and Technology, 1999.

[2] V. Merminod and F. Rowe, "How does PLM technology support knowledge transfer and translation in new product development? Transparency and boundary spanners in an international context," Inf. Organ., vol. 22, no. 4, pp. 295-322, Oct. 2012.

[3] M. Alavi and D. E. Leidner, "Review: Knowledge Management and Knowledge Management Systems: Conceptual Foundations and Research Issues," MIS Q., vol. 25, no. 1, pp. 107-136, Mar. 2001.

[4] C. Zins, "Conceptual Approaches for Defining Data, Information, and Knowledge: Research Articles," J Am Soc Inf Sci Technol, vol. 58, no. 4, pp. 479493, Feb. 2007.

[5] W. Liu, M. Maletz, Y. Zeng, and D. Brisson, Product Lifecycle Management: A Review. 2009.

[6] T. Bilgic and D. Rock, "Product Data Management Systems: ...," in Proceedings of the 1997 asme design engineering technical conferences and computers in engineering conference, 1997, pp. 97-3720.

[7] D. Ullman, The Mechanical Design Process, 4 edition. Boston: McGraw-Hill Science/Engineering/Math, 2009. 
[8] G. Vijaykumar and A. Chakrabarti, "Understanding the Knowledge Needs of Designers During Design Process in Industry," J. Comput. Inf. Sci. Eng., vol. 8, no. 1, pp. 011004-011004, février 2008.

[9] S. K. Chandrasegaran, K. Ramani, R. D. Sriram, I. Horváth, A. Bernard, R. F. Harik, and W. Gao, "The evolution, challenges, and future of knowledge representation in product design systems," Comput.-Aided Des., vol. 45, no. 2, pp. 204-228, Feb. 2013.

[10] D. Baxter, J. Gao, K. Case, J. Harding, B. Young, S. Cochrane, and S. Dani, "An engineering design knowledge reuse methodology using process modelling," Res. Eng. Des., vol. 18, no. 1, pp. 37-48, Apr. 2007.

[11] F. Demoly, H. J. Pels, and S. Gomes, "Proactive Engineering and PLM: Current Status and Research Challenges," in Product Lifecycle Management for Society, A. Bernard, L. Rivest, and D. Dutta, Eds. Springer Berlin Heidelberg, 2013, pp. 170-181.

[12] M. O. Riedl and R. M. Young, "An Intent-Driven Planner for Multi-Agent Story Generation," in Proceedings of the Third International Joint Conference on Autonomous Agents and Multiagent Systems - Volume 1, Washington, DC, USA, 2004, pp. 186-193.

[13] R. Ganeshan, J. Garrett, and S. Finger, "A framework for representing design intent," Des. Stud., vol. 15, no. 1, pp. 59-84, Jan. 1994.

[14] Y. Zhang and X. Luo, "Semantic query and reasoning for design meta-intent information," presented at the 2010 3rd IEEE International Conference on Computer Science and Information Technology (ICCSIT), 2010, vol. 9, pp. 672-676.

[15] M. Bazire and P. Brézillon, "Understanding Context Before Using It," in Modeling and Using Context, A. Dey, B. Kokinov, D. Leake, and R. Turner, Eds. Springer Berlin Heidelberg, 2005, pp. 29-40.

[16] D. Monticolo, "Une approche organisationnelle pour la conception d'un système de gestion des connaissances fondé sur le paradigme agent," Université de Technologie de Belfort-Montbeliard, 2008.

[17] J. S. Lee and J. C. Lee, "Context Awareness by Case-Based Reasoning in a Music Recommendation System," in Ubiquitous Computing Systems, H. Ichikawa, W.-D. Cho, I. Satoh, and H. Y. Youn, Eds. Springer Berlin Heidelberg, 2007, pp. 4558.

[18] G. Pezzulo, M. V. Butz, C. Castelfranchi, and R. Falcone, "Introduction: Anticipation in Natural and Artificial Cognition," in The Challenge of Anticipation, Springer Berlin Heidelberg, 2008, pp. 3-22.

[19] Y. Chen, M. Zhao, Y. Xie, and Z. Zhang, "A new model of conceptual design based on Scientific Ontology and intentionality theory. Part II: The process model," Des. Stud., vol. 38, pp. 139-160, May 2015.

[20] M. V. Butz, O. Herbort, and G. Pezzulo, "Anticipatory, Goal-Directed Behavior," in The Challenge of Anticipation, C. Castelfranchi and R. Falcone, Eds. Springer Berlin Heidelberg, 2008, pp. 85-113.

[21] F. Demoly, X.-T. Yan, B. Eynard, L. Rivest, and S. Gomes, "An assembly oriented design framework for product structure engineering and assembly sequence planning," Robot. Comput.-Integr. Manuf., vol. 27, no. 1, pp. 33-46, Feb. 2011. 
[22] S.-H. Li, J.-L. Chen, D. C. Yen, and Y.-H. Lin, "Investigation on auditing principles and rules for PDM/PLM system implementation," Comput Ind, vol. 64, no. 6, pp. 741-753, août 2013.

[23] S. Khodaygan, M. R. Movahhedy, and M. S. Fomani, "Tolerance analysis of mechanical assemblies based on modal interval and small degrees of freedom (MISDOF) concepts," Int. J. Adv. Manuf. Technol., vol. 50, no. 9-12, pp. 1041-1061, Oct. 2010.

[24] R. S. Michalski, H. Ko, and K. Chen, "Qualitative Prediction: The SPARC/G Methodology for Inductively Describing and Predicting Discrete Processes," 1986.

[25] K.-Y. Kim and Y. S. Kim, "Causal design knowledge: Alternative representation method for product development knowledge management," Comput.Aided Des., vol. 43, no. 9, pp. 1137-1153, Sep. 2011.

[26] A. K. Dey, "Understanding and Using Context, Personal and Ubiquitous Computing," pp. 5(1), 4-7., 2001. 